\title{
Letter visibility and word recognition: The optimal viewing position in printed words
}

\author{
TATJANA A. NAZIR \\ Institut fur Psychologie der RWTH Aachen, Germany \\ and Groupe Regard Laboratoire de Psychologie Experimentale, CNRS, Paris, France \\ and \\ DIETER HELLER and CLAUDIA SUSSMANN \\ Institut fur Psychologie der RWTH Aachen, Germany
}

\begin{abstract}
It has repeatedly been shown that the time and accuracy of recognizing a word depend strongly on where in the word the eye is fixating. Word-recognition performance is maximal when the eye fixates a region near the word's center, and decreases to both sides of this "optimal viewing position." The reason for this phenomenon is assumed to be the strong drop-off of visual acuity: the visibility of letters decreases with increasing eccentricity from fixation location. Consequently, fewer letters can be identified when the beginning or ending of a word is fixated than when its center is fixated. The present study is a test of this visual acuity hypothesis. If the phenomenon is caused by letter visibility, then it should be sensitive to variations of visual conditions in which the letters are presented. By increasing the interletter distances of the word (e.g., $\left.\mathbf{a}_{-} \mathbf{t}_{-} \mathbf{t}_{-} \mathbf{e}_{-} \mathbf{m}_{-} \mathbf{p}_{-} \mathbf{t}\right)$, letter visibility was decreased. As expected from our hypothesis, the viewing-position effect became more exaggerated. An additional experiment showed that destroying word-shape information (e.g., aTtEmPt) decreased overall word-recognition performance but had no influence on the viewingposition effect. Varying the viewing position in words might thus be used as a paradigm, allowing one to separate out the contribution of letter information and supraletter information to word recognition.
\end{abstract}

O'Regan and his collaborators (Nazir, in press; Nazir, O’Regan, \& Jacobs, 1991; O'Regan \& Jacobs, 1992; O'Regan \& Lévy-Schoen, 1987; O'Regan, Lévy-Schoen, Pynte, \& Brugaillère, 1984; Vitu, 1991; Vitu, O'Regan, \& Mittau, 1990) and McConkie, Kerr, Reddix, Zola, and Jacobs (1989) have repeatedly shown that the speed and accuracy of word recognition depend strongly on where in the word the eye is fixating. The probability that a word is recognized during only one fixation is highest when the eye fixates near the word's center, and decreases dramatically as the eye's initial fixation position deviates from this "convenient" or "optimal" viewing position. The more the first fixation location is shifted toward the beginning or the ending of a word, the higher the necessity for making an additional fixation in the word in order to recognize it correctly. According to recent estimations, the total time the eye spends on a word increases for about $20 \mathrm{msec}$ with each letter of deviation from the optimal position (O'Regan \& Lévy-Schoen, 1987; O’Regan et al., 1984).

The primary basis of this optimal viewing position (OVP) phenomenon is assumed to be the drop-off of pe-

This study was supported by a grant from the Deutsche Forschungsgemeinschaft to D. Heller and A. Jacobs. We wish to thank Arthur Jacobs for helpful comments. Address correspondence to T. A. Nazir or D. Heller, Institut für Psychologie der RWTH Aachen, Jägerstr. 17-19, D-5100 Aachen, Germany. ripheral acuity (McConkie et al., 1989; Nazir et al., 1991; O'Regan, 1989, 1990; O'Regan \& Jacobs, 1992). Since, up to at least $10^{\circ}$, the minimum angle of resolution increases nearly as a linear function of the distance from the center of vision (Jacobs, 1979; Olzak \& Thomas, 1986), a maximum of visual information should be available from the word while its center is being fixated. Following this logic, McConkie et al. (1989) proposed a simple model to account for the obtained word-recognition data. This working model rests on the assumptions that the total amount of visual information available from a word is the sum of the information available from all its letters and that the amount of visual information obtained from a letter decreases as a linear function of its distance from fixation location. The application of this model is shown in Table 1 (example taken from McConkie et al., 1989) and Figure 1 (see also Nazir, 1991; Nazir et al., 1991). Table 1 presents the hypothetical amount of information available from individual letters in a 7-letter word, assuming that the amount of extractable visual information from the directly fixated letter has the value of 1 , and that there is a drop of $10 \%$ (an arbitrarily chosen value) in information for each letter position unit of distance from that location. The total amount of visual information obtained from the word is the sum of the information obtained from the individual letters. As is evident from Figure 1, the amount of available visual information varies with the location of the eye in the word; 
Table 1

Amount of Visual Information Available From Individual Letters in a 7-Letter Word

\begin{tabular}{|c|c|c|c|c|c|c|c|c|}
\hline \multirow{2}{*}{$\begin{array}{l}\text { Letter Position } \\
\text { Fixated in Word }\end{array}$} & \multicolumn{7}{|c|}{ Position of Letter in 7-Letter Word } & \multirow{2}{*}{$\begin{array}{c}\text { Total Visual } \\
\text { Information Available } \\
\text { From Word }\end{array}$} \\
\hline & 1 & 2 & 3 & 4 & 5 & 6 & 7 & \\
\hline 1 & 1 & 9 & .8 & .7 & .6 & .5 & 4 & 4.9 \\
\hline 2 & 9 & 1 & .9 & .8 & .7 & .6 & .5 & 5.5 \\
\hline 3 & .8 & .9 & 1 & .9 & .8 & .7 & .6 & 5.7 \\
\hline 4 & .7 & .8 & .9 & 1 & .9 & .8 & .7 & 5.8 \\
\hline 5 & .6 & .7 & .8 & .9 & 1 & .9 & .8 & 5.7 \\
\hline 6 & .5 & .6 & .7 & .8 & .9 & 1 & .9 & 5.4 \\
\hline 7 & .4 & .5 & .6 & .7 & .8 & .9 & 1 & 4.9 \\
\hline
\end{tabular}

Note-Assumptions: The amount of visual information from the directly fixed letter is equal to 1 ; this information drops by .1 for each letter position of eccentricity. Word information is the sum of letter information (see McConkie et al., 1989).

it is maximal when the center of the word is fixated, and decreases the more the fixation location deviates to one side or the other.

So far, the model seems to fit perfectly the empirical results from different paradigms, including reading, naming, and lexical decision: when the eye fixates the location in the word where the model predicts a maximum of available visual information, refixation probability during normal reading is minimal (McConkie et al., 1989;

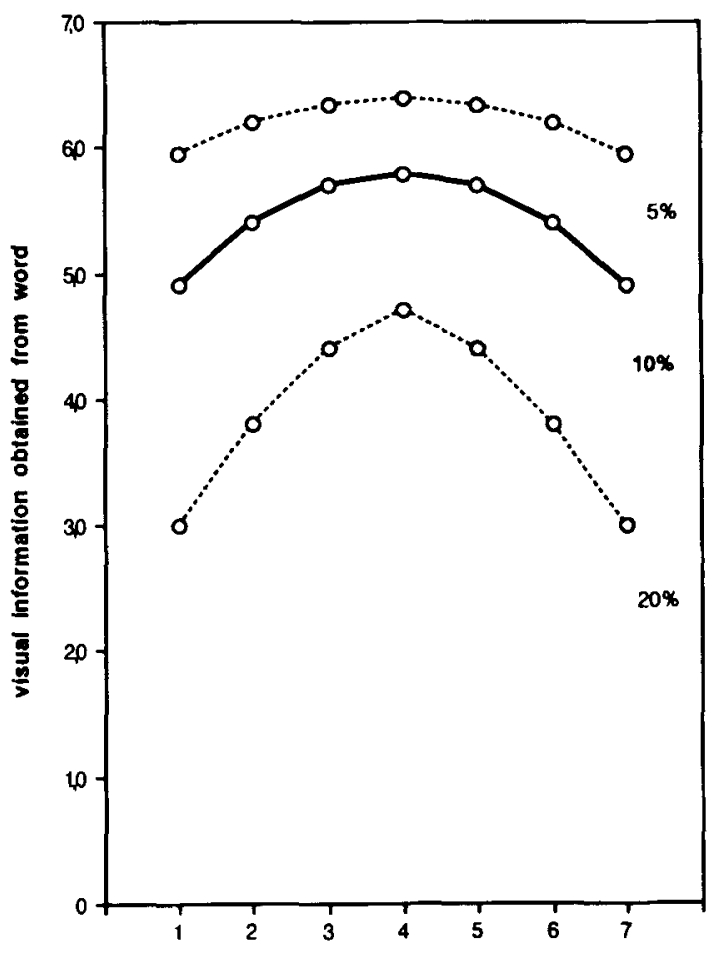

position of fixated letter in the word

Figure 1. Theoretical distribution of the total amount of visual information available from a word as a function of fixation location in the word. The assumption here is that the amount of visual information obtained from the letters drops by $5 \%, 10 \%$, or $20 \%$ with each letter position of eccentricity (see text for further details).
O'Regan et al., 1984; O'Regan \& Lévy-Schoen, 1987; Vitu, 1991; Vitu et al., 1990), naming latencies and lexical decision time (when the eye is free to move in the word) are shortest (Brysbaert \& d'Ydewalle, 1988; O'Regan \& Jacobs, 1992; O'Regan et al., 1984), and the probability of correct lexical decision, when only one fixation is allowed in the word, is highest (Nazir, in press; Nazir et al., 1991). However, the model has not yet been tested directly. The main assumption of the model is that the OVP phenomenon is a function of letter visibility ${ }_{\uparrow}$ In the example given by McConkie et al., the amount of visual information available from a letter drops by a value of $10 \%$ with each letter position of eccentricity. The resulting distribution of total visual information available from different locations in a word describes a parabolic curve of a given height and shape (see Figure 1). The drop-off rate of available letter information is determined by acuity and can be manipulated by changing the visual presentation conditions of the stimulus. If the visibility of the letters is reduced (e.g., by adding noise) the drop-off rate increases. The model predicts that changing the drop-off rate will change the curve of total visual information available from the word. If, instead of $10 \%$, the information available from a letter drops by a value of $5 \%$ or $20 \%$, the height and the shape of the curves in Figure 1 change (see Figure 1 dashed curves). The higher the drop-off rate, the steeper the curve. Thus, if, as assumed by the model, the OVP phenomenon is related to letter visibility, this phenomenon should become more exaggerated when letter visibility is reduced. To test this, in the following study, word-recognition performance was measured as a function of fixation location in the word while the drop-off rate of available visual information from letters in the word was varied.

A simple way of manipulating the drop-off rate of available visual information from letters in a word, without making the reading task too artificial, is to change interletter spacing. Increasing the space between two letters automatically increases the eccentricity of the letters, which in turn decreases their visibility; when the first letter of a normally spaced word is fixated, its last letter is less eccentric than the last letter of a widely spaced word (e.g., word vs. $w_{-} o_{-} r_{-}$d). Thus, word-recognition performance should be worse for a widely spaced word than 
for a normally spaced word. However, the visibility of a stimulus is determined not only by its eccentricity, but also by lateral masking (e.g., Bouma, 1970, 1978; Jacobs, 1979). For a given eccentricity, a stimulus (e.g., a letter) is recognized best when it is presented in isolation. If the stimulus is flanked by nearby contours (e.g., other letters of the word), its visibility decreases. The interaction affecting a stimulus becomes stronger the smaller the distance between stimulus and flankers, and is more pronounced in peripheral vision than in central vision (e.g., Bouma, 1970). Thus, increasing interletter spacing decreases lateral masking, which in turn should increase letter visibility. To estimate the reciprocal influence of interletter spacing on letter visibility, the probability of recognizing a letter was first measured in a string of homogeneous letters, while interletter spacing was varied (Experiment 1). From these data, word-recognition performance for words with different interletter spacings were estimated and compared with empirical data on word recognition (Experiment 2).

\section{EXPERIMENT 1}

To obtain an empirical estimate of letter visibility under several conditions of interletter spacings, we chose a letter-identification task in which the subject identified a target letter presented at different locations in a 12-letter string of xs, presented either to the right or to the left of fixation location.

\section{Method}

Subjects. Twelve unpaid German students from the University of Aachen participated in this experiment for course credit. All had normal or corrected-to-normal vision.

Materials. Strings of 12 lowercase letter xs served as stimuli. In each string, one letter was replaced by one of the following 10 target letters: a, c, e, m, n, o, r, s, w, or $\mathrm{z}$. These target letters could appear at the 3rd, 5th, 7th, 9th, or 11 th position in the string. On the average, the letters were $.29^{\circ}$ high and $.18^{\circ}$ wide, at a viewing distance of $60 \mathrm{~cm}$. Five different interletter spaces were chosen, subtending $.06^{\circ}, .12^{\circ}, .18^{\circ}, .24^{\circ}$, and $.30^{\circ}$, respectively. Note that the degree of eccentricity of the target letter at a given string location (e.g., the 3rd letter in the string) increases with increasing interletter spaces. In an additional control condition, target letters were presented in isolation, at either $.48^{\circ}, 1.18^{\circ}, 2.12^{\circ}, 3.28^{\circ}$, or $4.69^{\circ}$. The stimuli were presented on a black and white Atari video monitor, refreshed at $70 \mathrm{~Hz}$.

Design and Procedure. A fixation point appeared at the center of a computer screen for $360 \mathrm{msec}$ ( 25 refresh cycles) and was then replaced by a letter string presented for $115 \mathrm{msec}$ ( 8 cycles; the limited presentation duration was adopted to prevent subjects from making eye movements), followed by a mask ( 12 \#s), which remained on the screen until the subject pressed a response button. The letter string appeared such that the directly fixated location was either the first letter (thus, the target appeared to the right of fixation) or the last letter of the string (target appeared to the left). In the isolated-presentation condition, a single letter appeared at one of the specified eccentricities. The subject's task was to identify the target letter in the string by typing the corresponding key on the computer keyboard. Each of the 10 target letters appeared once at each of the five specified locations in the five different interlet- ter space conditions and the isolated-presentation condition, to both sides of fixation location. Thus, in all, there were 600 trials per subject $(10 \times 5 \times 6 \times 2=600)$. The position of the target letter in the string, the interletter distance, and the presentation side of the string (right or left of fixation) were randomized. The subjects used a chinrest

\section{Results and Discussion}

Isolated letter condition. Table $2 \mathrm{~A}$ shows the results of the isolated-letter identification. An analysis of variance (ANOVA) showed a significant effect of eccentricity $[F(4,44)=48.57, p<.01]$. Neither the effect of presentation side nor the interaction between presentation side and eccentricity was significant $[F(1,11)=0.283$, and $F(4,44)=0.404$, respectively]

Letter-in-string condition. Tables $2 \mathrm{~B}$ and $2 \mathrm{C}$ show the results of the letter-in-string identification, left and right of fixation, respectively. There was a significant effect of presentation side of the target, left or right of fixation $[F(1,11)=7.324, p<.025]$, target location in the string $[F(4,44)=333.6, p<.01]$, and interletter space $[F(4,44=8.817, p<.01]$. Neither the interaction between target location and interletter space nor the interaction between presentation side and interletter space was significant $[F(16,176)=1.57$ and $F(4,44)=0.898$, respectively). The interaction between target location and presentation side was significant at $p<.05[F(4,44)=$ 2.676]. These results will be discussed later in greater detail.

Left/right asymmetry. In the letter-in-string task, performance was globally better when the target had to be identified to the right of fixation. This superiority of the right visual field in recognizing letters has been reported before (e.g., Bouma, 1973; Bouma \& Legein, 1977; Hagenzieker, van der Heijden, \& Hagenaar, 1990; Nazir et al., 1991) and is consistent with classical results on perceptual span during reading. The number of letters utilized during a fixation differ depending on whether they are to the left or to the right of fixation. To the left of fixation, only a few letters are used; to the right, however, the perceptual span probably extends to 10-15 letters (McConkie \& Rayner, 1976; Rayner, Well, \& Pollatsek, 1980; Underwood \& McConkie, 1985). In accordance with Bouma and Legein's (1977) results, no asymmetry was obtained for the isolated-letter condition. It seems

Table 2 A

Percent Correct Letter Identification and Standard Deviation for the Isolated-Letter Condition

\begin{tabular}{cccccc}
\hline & \multicolumn{2}{c}{$\begin{array}{c}\text { Presentation } \\
\text { to the Left } \\
\text { of Fixation }\end{array}$} & & \multicolumn{2}{c}{$\begin{array}{c}\text { Presentation } \\
\text { to the Right } \\
\text { of Fixation }\end{array}$} \\
\cline { 2 - 6 } (in degrees) & \% Correct & $S D$ & & \% Correct & $S D$ \\
\hline .48 & 99.2 & 2.9 & & 98.3 & 3.9 \\
1.18 & 95.8 & 6.7 & 93.3 & 7.8 \\
2.12 & 90.8 & 10.0 & 90.0 & 8.5 \\
3.28 & 74.2 & 11.6 & 76.7 & 9.8 \\
4.69 & 64.2 & 18.3 & & 61.7 & 15.3 \\
\hline
\end{tabular}


Table 2B

Percent Correct Letter Identification and Standard Deviations as a Function of Target Location in the String, for the Five Interletter Distances; Data Show Performance to the Left of Fixation

\begin{tabular}{|c|c|c|c|c|c|c|c|c|c|c|}
\hline \multirow{3}{*}{$\begin{array}{c}\text { Interletter } \\
\text { Distance } \\
\text { (in degrees) }\end{array}$} & \multicolumn{10}{|c|}{ Letter Location in the String } \\
\hline & \multicolumn{2}{|l|}{3} & \multicolumn{2}{|l|}{5} & \multicolumn{2}{|c|}{7} & \multicolumn{2}{|l|}{9} & \multicolumn{2}{|l|}{11} \\
\hline & $\%$ Correct & $S D$ & $\%$ Correct & $S D$ & $\%$ Correct & $S D$ & $\%$ Correct & $S D$ & $\%$ Correct & $S D$ \\
\hline .06 & 88.3 & 14.0 & 64.2 & 13.1 & 44.2 & 13.8 & 27.5 & 11.4 & 18.3 & 14.7 \\
\hline .12 & 90.8 & 7.9 & 73.3 & 10.7 & 52.5 & 13.6 & 29.2 & 14.4 & 17.5 & 12.2 \\
\hline .18 & 90.8 & 12.4 & 70.0 & 17.6 & 44.2 & 16.8 & 23.3 & 9.8 & 12.5 & 8.7 \\
\hline .24 & 91.7 & 9.4 & 62.5 & 16.0 & 43.3 & 15.6 & 22.5 & 10.6 & 10.8 & 7.9 \\
\hline .30 & 89.2 & 10.8 & 62.5 & 9.7 & 35.0 & 21.5 & 19.2 & 12.4 & 12.5 & 8.7 \\
\hline
\end{tabular}

Table 2C

Percent Correct Letter Identification and Standard Deviations as a Function of Target Location in the String, for the Five Interletter Distances; Data Show Performance to the Right of Fixation

\begin{tabular}{|c|c|c|c|c|c|c|c|c|c|c|}
\hline \multirow{3}{*}{$\begin{array}{c}\text { Interletter } \\
\text { Distance } \\
\text { (in degrees) }\end{array}$} & \multicolumn{10}{|c|}{ Letter Location in the String } \\
\hline & \multicolumn{2}{|l|}{3} & \multicolumn{2}{|l|}{5} & \multicolumn{2}{|c|}{7} & \multicolumn{2}{|l|}{9} & \multicolumn{2}{|l|}{11} \\
\hline & \% Correct & $S D$ & $\%$ Correct & $S D$ & \% Correct & $S D$ & \% Correct & $S D$ & $\%$ Correct & $S D$ \\
\hline .06 & 94.2 & 9.0 & 73.3 & 21.5 & 40.0 & 18.1 & 31.7 & 14.7 & 24.2 & 17.3 \\
\hline .12 & 94.2 & 10.0 & 71.7 & 21.2 & 45.0 & 20.7 & 33.3 & 12.3 & 22.5 & 12.9 \\
\hline .18 & 95.0 & 10.0 & 76.7 & 15.0 & 45.8 & 17.8 & 27.5 & 12.9 & 20.0 & 8.5 \\
\hline .24 & 91.7 & 8.3 & 71.7 & 19.0 & 37.5 & 14.8 & 24.2 & 11.6 & 15.0 & 10.9 \\
\hline .30 & 91.7 & 9.4 & 68.3 & 16.4 & 35.8 & 17.8 & 15.0 & 10.9 & 21.7 & 12.7 \\
\hline
\end{tabular}

likely that the difference between recognizing letters (presented in strings) to the left and right of fixation is related to reading habits (Nazir, in press). At least with regard to visual span, the asymmetry is reversed for subjects reading Hebrew (Pollatsek, Bolozky, Well, \& Rayner, 1981). However, it is not the purpose of the present study to understand the mechanisms underlying this asymmetry. Its implication for the OVP phenomenon will be discussed later. In the following estimate of the influence of interletter space on letter visibility, the asymmetry will not be considered.

Letter visibility under different interletter space conditions. Figure 2 shows the percentage of correctly identified letters (averaged over both presentation sides) for the isolated-letter condition and the five different interletter spaces as a function of degree of eccentricity. For each of the different conditions, performance decreases with increasing distance of the target from fixation location. However, at a given degree of eccentricity, performance is worst for the smallest interletter space and improves with space between the letters. Performance is maximal in the isolated-letter condition. Thus, these data are consistent with the results obtained by Bouma (1970) in showing that lateral masking is stronger when the space between neighboring contours is smaller.

However, if we consider performance not as a function of degrees of eccentricity but as a function of letter position in the string (e.g., the 7th letter), letter identification is not necessarily better when the interletter spacing is larger. To show the influence of interletter spacing on the visibility of a letter at a given string location, Figure 3 plots performance at the five tested locations ( $3 \mathrm{rd}$, 5th, 7th, 9th, and 11 th letter positions) as a function of the five interletter spacings. For the 3rd and 5th letter positions, the effect of interletter spacing was not significant $[F(4,44)=0.367$ and $F(4,44)=1.864$, respectively]. However, at the 7 th and 9th letter positions, performance decreased with increasing interletter spacing $[F(4,44)=3.551, p<.025$, and $F(4,44)=7.004$, $p<.01$, respectively]; for both positions, a trend analysis showed a significant linear trend as a function of interletter spacing $[F(1,11)=5.65, p<.05$, and $F(1,11)=$ 28.193]. For the 11 th letter position, the effect just failed to be significant $[F(4,44)=2.489, p<.1]$. This nonsignificant effect for the largest letter location was probably caused by the overall low performance at this position, which for all interletter spacings is almost at chance level.

Thus, at locations near the fixation point, decreasing resolution is compensated for by decreasing lateral masking: the probability of identifying the target letter at String Locations 3 and 5 is equally good for the different interletter spaces, although the distance of the target to the center of vision increases with increasing interletter spaces. However, at locations farther away from fixation (7th, 9th, and 11th letter positions), letter-identification performance clearly decreases with increasing interletter spaces.

To assess word-recognition performance under different conditions of interletter spaces, we have to consider letter identification not as a function of degrees of eccentricity but as a function of letter location in the string. Let us remember the assumption of McConkie et al.'s (1989) model-that in order to recognize a word, visual 


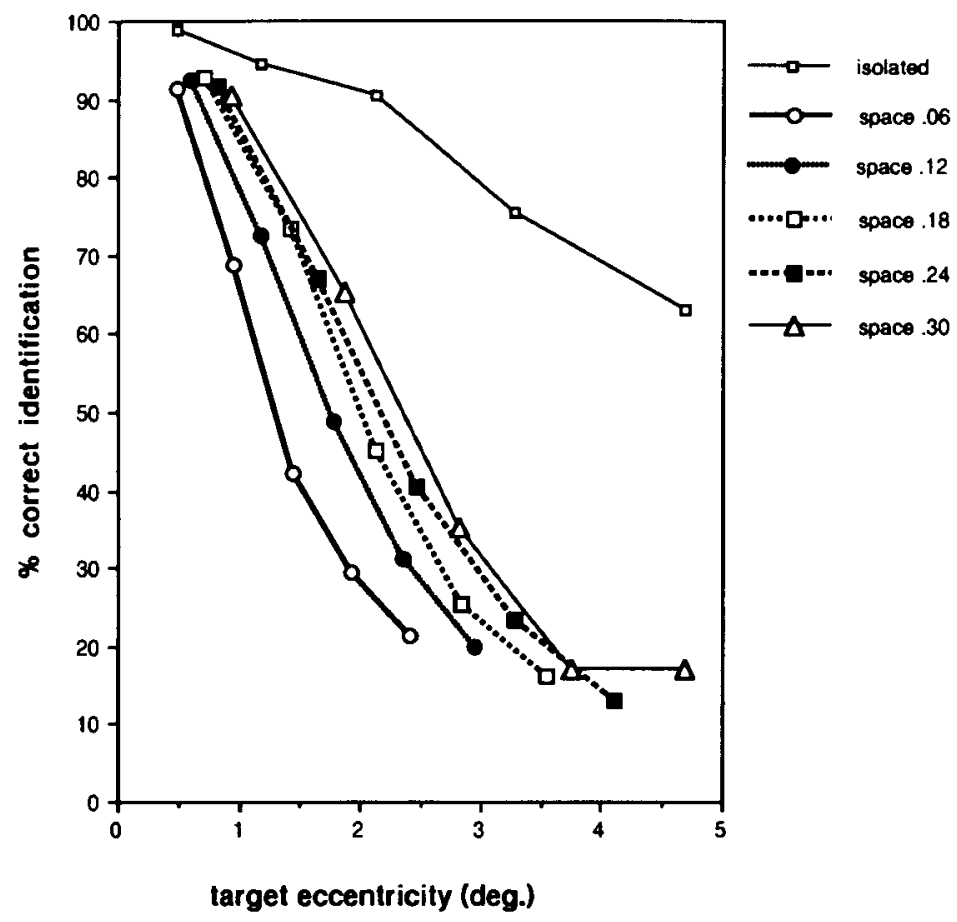

Figure 2. Percent correct letter identification as a function of target eccentricity for the isolated-letter condition and the five different interletter spacings $\left(.06^{\circ}\right.$, $.12^{\circ}, .18^{\circ}, 24^{\circ}$, and $.30^{\circ}$ ).

information is collected from all the letters of the word. Consequently, in conditions where an effect of interletter spacing was found in the letter-in-string experiment, an effect should be found in a word-recognition task as well. Thus, if the OVP phenomenon is related to letter visibility, as assumed in the model, increasing interletter spaces in words should exaggerate the phenomenon, provided that the words are sufficiently long. Experiment 2 tested this.

\section{EXPERIMENT 2}

To test if the OVP phenomenon is related to letter visibility, word-identification performance was measured in Experiment 2 as a function of fixation location in the word while interletter spacing was varied. The location where the eye fixates the word was manipulated experimentally and, to ensure that information was taken only from this location, presentation duration of the word was limited to allow only one fixation. To have visual conditions that were comparable to those of Experiment 1, this duration was set to $115 \mathrm{msec}$ and word presentation was followed by a mask as well. The word stimuli used were presented with three different interletter spacings: the smallest $\left(.06^{\circ}\right)$, the largest $\left(.30^{\circ}\right)$, and the intermediate $\left(.18^{\circ}\right)$ spaces that were used in Experiment 1. The length of the words were 5 (short words), 9, and 11 letters (long words). Because in the letter-in-string experiment no effect of interletter space was obtained up to the 5th letter location, for the 5-letter words we expected no effect of interletter space variation. For longer words, however, identification performance was expected to vary more with fixation location the more the interletter space increased.

\section{Method}

Subjects. Fifteen unpaid German students from the University of Aachen participated in this experiment for course credit. All had normal or corrected-to-normal vision. Most, but not all, of the subjects had participated in Experiment 1.

Materials. One hundred fifty 5-, 9-, and 11-letter common German words (average frequency ranged from 8.6 to 232 per million; Meier, 1964) served as stimuli. The words were divided into three lists; each list contained 50 words of each length. The typography as well as the size of the letters were identical to those used in Experiment 1.

Design. The experiment contained three blocks. In each block, the words of one of the three lists were presented with one of three interletter spaces: $.06^{\circ}, .18^{\circ}$, or $.30^{\circ}$. A word could be presented so that the eye fixated the middle of one of five equal zones in the word (e.g., for the smallest interletter space condition, the zones for the 5-letter words were 1 letter wide; for the 9-letter words, they were 1.8 letters wide). In each list, each word-length category was divided into five subgroups of 10 words; the subjects were divided into five subgroups of 3 persons each. A Latin-square design was used to determine which words were attributed to which first fixation zone for which subject. For each word length, each subject saw 10 different words presented at each of the five zones. Across all subjects, each word was seen an equal number of times from each fixation zone. Another Latin-square design was used to determine which of the three lists was attributed to which interletter space condition. Thus, each subject saw each of the 150 words only once. 


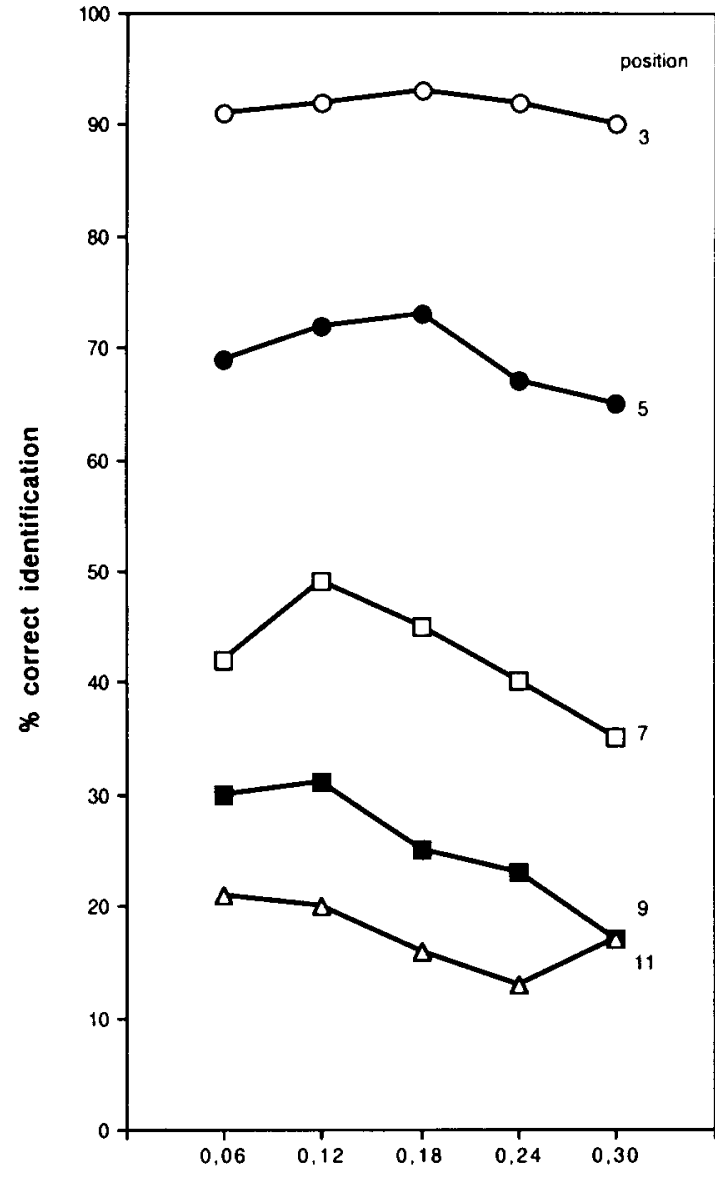

inter letter space (deg.)

Figure 3. Percent correct letter identification as a function of interletter space $\left(.06^{\circ}, .12^{\circ}, .18^{\circ}, .24^{\circ}\right.$, and $\left..30^{\circ}\right)$ for the five target positions in the string (3rd, 5th, 7th, 9th, and 11th letter positions).
Procedure. A fixation point appeared at the center of a computer screen for $360 \mathrm{msec}$ ( 25 cycles). It was then replaced by a word presented for $115 \mathrm{msec}$ and followed by a mask consisting of a string of \#s covering the area where the word had appeared. The mask remained on the screen until the subject pressed a specified key on the keyboard, which triggered the next trial. The word string appeared to be shifted horizontally with respect to the fixation point in such a way that, upon its appearance, the subject's eye was positioned on the center of one of the five possible fixation zones. The subjects used a chinrest, and the viewing distance was $60 \mathrm{~cm}$. The task was to read the word aloud, and the answers were noted by the experimenter. Probability of correct word identification was measured.

\section{Results and Discussion}

In Figure 4, probability of correct word identification for the three different interletter spacings is shown as a function of fixation location in the word. Figure 4 gives the data for the 5-, 9-, and 11-letter words. Performance for the short 5-letter words was almost always $100 \%$. Because of this ceiling effect, the data cannot be interpreted with respect to the experimental manipulation. For longer words, however, a clear effect of interletter space and fixation location was obtained. For the 9-letter words, the effect of interletter space $[F(2,28)=72.573, p<.01]$ and fixation location $[F(4,56)=47.117, p<.01]$ were significant. The interaction between these two factors, which indicates a change in the shape of the curves, was significant as well $[F(8,112)=5.716, p<.01]$. Similar results were obtained for the 11-letter words $[F(2,28)=52.027, p<.01$, for the interletter space; $F(4,56)=63.792, p<.01$, for fixation location; and $F(8,112)=5.069, p<.01$, for the interaction between these two factors]. A trend analysis showed a significant quadratic trend for both the 9- and 11-letter words $[F(1,14)=166.32, p<.01$, and $F(1,14)=200.51$, $p<.01$, respectively]. The interactions between the quadratic trend and interletter space, which is a further and stronger indicator of a change of the shapes of the
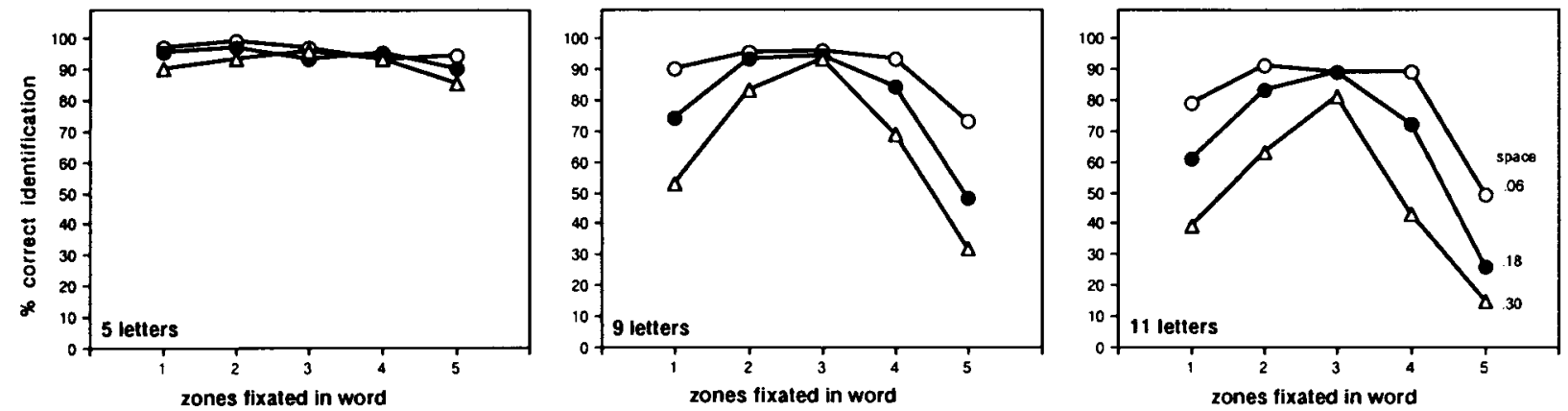

Figure 4. Percent correct word identification as a function of fixated zones in the word for the three different interletter spacings $\left(.06^{\circ}\right.$, $.18^{\circ}$, and. $\mathbf{3 0}^{\circ}$ ). Note that Zone 3 indicates performance while the eye is fixating the 3rd letter in 5-letter words, the 5th letter in 9-letter words, and the 6th letter in 11-letter words. 
Table 3

Estimated Values of the Parameters A, B, and $C$ (With an Interval of Confidence of 95\%) and the Multiple $r^{2}$ as a Function of Interletter Distances for the 9- and 11-Letter Words as a Result of Fitting the Model Specified by Equation 1 to the Curves Given in Figure 4

\begin{tabular}{|c|c|c|c|c|}
\hline \multirow{2}{*}{$\begin{array}{c}\text { Interletter } \\
\text { Distance } \\
\text { (in degrees) } \\
\end{array}$} & \multicolumn{4}{|c|}{ Parameter } \\
\hline & $A$ & $B$ & $C$ & $r^{2}$ \\
\hline \multicolumn{5}{|c|}{9 Letters } \\
\hline $\begin{array}{l}.06 \\
.18 \\
.30\end{array}$ & $\begin{array}{l}98.2(94.0-102.4) \\
97.1(91.2-103.1) \\
91.1(84.1-97.9)\end{array}$ & $\begin{array}{r}-3.95(-5.64--2.26) \\
-8.67(-11.0--6.34) \\
-12.14(-14.81--9.48)\end{array}$ & $\begin{array}{l}2.54(2.21-2.89) \\
2.65(2.46-2.83) \\
2.77(2.63-2.91)\end{array}$ & $\begin{array}{l}.982 \\
.959 \\
.931\end{array}$ \\
\hline \multicolumn{5}{|c|}{11 Letters } \\
\hline $\begin{array}{l}.06 \\
.18 \\
.30\end{array}$ & $\begin{array}{l}95.2(88.7-101.6) \\
90.6(83.0-98.2) \\
71.7(64.7-78.8)\end{array}$ & $\begin{array}{r}-7.19(-9.75--4.62) \\
-11.38(-14.36--8.40) \\
-11.33(-14.1--8.59)\end{array}$ & $\begin{array}{l}2.57(2.31-2.83) \\
2.64(2.46-2.82) \\
2.69(2.53-2.86)\end{array}$ & $\begin{array}{l}.952 \\
.916 \\
.879\end{array}$ \\
\hline
\end{tabular}

curves as a function of spacing, were significant as well $[F(2,28)=19.38, p<.01$, and $F(2,28)=5.32, p<$ .025 , for 9 - and 11-letter words, respectively).

To determine the slopes and intercepts of the curves (Figure 4), the data, of the 9- and 11-letter words, were fitted using a standard model-fitting procedure (quasiNewton) to the following model:

$$
Y=A+B(X-C)^{2} \text {. }
$$

In this equation, Parameter $A$ indicates the vertical offset of the curve at its highest point, $B$ determines the slope of the curve at a given point, and $C$ indicates the letter position in the word (on the $x$-axis) where the curve reaches its maximum-the optimal viewing position. Table 3 contains estimates of these three parameters. As expected from McConkie et al.'s (1989) model, Parameters $A$ and $B$ decrease when letter visibility decreases. Thus, the expected effect occurred: the OVP phenomenon becomes more exaggerated with decreasing letter visibility (e.g., increasing interletter space).

Interestingly, the location of the OVP (indicated by $\mathrm{Pa}$ rameter $C$ ) is not exactly in the center of the word, but slightly to the left of it. (If it had been in the center, Parameter $C$ should have the value of 3 , which indicates the center of Zone 3. But, as is evident from Table 3, $C$ varies between 2.5 and 2.8.) This leftward shift of the OVP has been reported before (Nazir, in press; Nazir, et al., 1991; O'Regan \& Jacobs, 1992; O'Regan \& Lévy-Schoen, 1987; O'Regan et al., 1984). The fact that the optimal viewing position is not at the center of the words seems, at first thought, to contradict the explanation of the phenomenon in terms of pure visual factors (see O'Regan, 1989, 1990; O'Regan \& Lévy-Schoen, 1987). Since acuity decreases equally to both sides of the center of vision, the OVP should be in the center of the word. However, as mentioned before and as supported by the results of Experiment 1, letters to the right of fixation are better recognized than those to the left of fixation (Bouma, 1973; Bouma \& Legein, 1977; Hagenzieker et al., 1990; Nazir et al., 1991). Whatever the reasons for this superiority of the right visual field, given this asymmetry, it is in fact advantageous to fixate slightly left of center so that fewer letters to the left of fixation have to be identified. Nazir et al. (1991) showed that, taking into account this left/right asymmetry of letter visibility, a slightly modified version of McConkie et al.'s model predicts perfectly the OVP phenomenon in word recognition.

Because of the unsatisfying results for the short, 5-letter words, a second pair of experiments were run. Due to a reduction of presentation duration from $115 \mathrm{msec}$ to $85 \mathrm{msec}$, overall performance was lowered to prevent the ceiling effect. A letter-in-string identification experiment (Experiment 3) was run first. The results of this experiment were then taken to estimate word-recognition performance as measured in Experiment 4.

\section{EXPERIMENT 3}

\section{Method}

Subjects. Twelve unpaid German students from the University of Aachen participated in this experiment for course credit. All had normal or corrected-to-normal vision.

Materials, Design, and Procedure. The materials, design, and procedure of Experiment 3 were identical to those of Experiment 1. The only differences were that presentation duration of the stimulus string was reduced to $85 \mathrm{msec}$ and the location of the target in the string was either at the 4th, 5th, 7th, or 9th letter position. In the isolated-letter condition, the target appeared at $.71^{\circ}, 1.18^{\circ}$, $2.46^{\circ}$, or $3.75^{\circ}$.

\section{Results and Discussion}

Isolated-letter condition. Table $4 \mathrm{~A}$ shows the results of the isolated-letter identification. The effect of eccentricity was significant $[F(3,33)=60.205, p<.01]$, but neither the effect of presentation side nor the interaction between presentation side and eccentricity was significant $[F(1,11)=3.13$ and $F(3,33)=.578]$.

Letter-in-string condition. Tables $4 \mathrm{~B}$ and $4 \mathrm{C}$ show the results of the letter-in-string identification, left and right of fixation, respectively. A separate analysis showed a significant effect of presentation side of the target (left or right of fixation) $[F(1,11)=36.442, p<.01]$, target location in string $[F(3,33)=121.569, p<.01]$, and interletter space $[F(4,44)=10.955, p<.01]$. None of 
Table 4A

Percent Correct Letter Identification and Standard Deviations for the Isolated-Letter Condition

\begin{tabular}{|c|c|c|c|c|}
\hline \multirow{2}{*}{$\begin{array}{l}\text { Letter Eccentricity } \\
\text { (in degrees) }\end{array}$} & \multicolumn{2}{|c|}{$\begin{array}{l}\text { Presentation } \\
\text { to the Left } \\
\text { of Fixation }\end{array}$} & \multicolumn{2}{|c|}{$\begin{array}{l}\text { Presentation } \\
\text { to the Right } \\
\text { of Fixation }\end{array}$} \\
\hline & $\%$ Correct & $S D$ & $\%$ Correct & $S D$ \\
\hline .71 & 87.5 & 10.6 & 90.0 & 13.5 \\
\hline 1.18 & 80.0 & 13.5 & 84.2 & 10.8 \\
\hline 2.46 & 55.0 & 22.4 & 65.0 & 19.8 \\
\hline 3.75 & 45.0 & 17.3 & 47.5 & 18.6 \\
\hline
\end{tabular}

the interactions were significant [target location and interletter space, $F(12,132)=12, .745$; presentation side and interletter space, $F(4,44)=2.099$; and target location and presentation side, $F(3,33)=2.585]$.

Left/right asymmetry. As was the case in Experiment 1 , performance was globally better when the target to be identified was to the right of fixation. However, the left/right asymmetry obtained was much stronger in this experiment than in Experiment 1 . Additionally, although statistically not significant, a superiority of the right visual field was obtained, even for the isolated-letter condition. Thus, the asymmetry effect becomes stronger when exposure duration is decreased.

Letter visibility under different interletter space conditions. Figure 5 shows the percentage of correctly identified letters (averaged over presentation sides) for the isolated-letter condition and the five different interletter spaces as a function of degree of eccentricity. The obtained results are comparable to those of Experiment 1 in showing that performance decreases with increasing eccentricity and increases with decreasing interletter spacing.

However, global performance was lower in Experiment 3 than in Experiment 1. To show the influence of interletter spacing on letter visibility, Figure 6 plots performance at the four tested locations as a function of the 5 interletter spacings. The effect of interletter spacing just failed to be significant for Letter Location $4[F(4,44)=$ $2.476, p<.1$, but was significant for Location 5 $[F(4,44)=4.683, p<.01]$ and Location $7[F(4,44)=$ $3.5, p<.025]$. It again just failed to be significant for Letter Location $9[F(4,44)=2.187, p<.1]$. As in Experiment 1 , the failure to find a significant effect for the farthest letter location might have been due to the overall low performance at that location. A trend analysis showed a significant linear trend for the 5th and 7th letter positions as a function of interletter spacing $[F(1,11)=9.697$, $p<.01$, and $F(1,11)=9.034, p<.025$, respectively].

With presentation duration reduced to $85 \mathrm{msec}$, an effect of interletter spacing is already obtained at a location four letters away from fixation. According to this result, even for short 5-letter words, variations of interletter spacing should affect word-recognition performance. In the following experiment, this prediction was tested using 5-, 7-, and 9-letter words.

\section{EXPERIMENT 4}

\section{Method}

Subjects. Fifteen unpaid German students from the University of Aachen participated in this experiment for course credit. All had normal or corrected-to-normal vision. Most, but not all, of the subjects had participated in Experiment 3.

Table 4B

Percent Correct Letter Identification and Standard Deviations as a Function of Target Location in the String, for the Five Interletter Distances; Data Show Performance to the Left of Fixation

\begin{tabular}{|c|c|c|c|c|c|c|c|c|}
\hline \multirow{3}{*}{$\begin{array}{l}\text { Interletter } \\
\text { Distance } \\
\text { (in degrees) }\end{array}$} & \multicolumn{8}{|c|}{ Letter Location in the String } \\
\hline & \multicolumn{2}{|l|}{4} & \multicolumn{2}{|c|}{5} & \multicolumn{2}{|c|}{7} & \multicolumn{2}{|l|}{9} \\
\hline & $\%$ Correct & $S D$ & \% Correct & $S D$ & $\%$ Correct & $S D$ & $\%$ Correct & $S D$ \\
\hline .06 & 58.3 & 21.2 & 45.8 & 23.5 & 23.3 & 18.3 & 20.0 & 15.4 \\
\hline .12 & 62.5 & 15.4 & 55.0 & 15.7 & 22.5 & 13.6 & 19.2 & 9.0 \\
\hline .18 & 61.7 & 16.4 & 47.5 & 25.3 & 30.0 & 11.3 & 20.0 & 11.3 \\
\hline .24 & 54.2 & 19.3 & 36.7 & 21.0 & 24.2 & 15.1 & 17.5 & 11.4 \\
\hline .30 & 55.8 & 17.3 & 33.3 & 14.4 & 23.3 & 14.3 & 12.5 & 13.6 \\
\hline
\end{tabular}

Table 4C

Percent Correct Letter Identification and Standard Deviations as a Function of Target Location in the String, for the Five Interletter Distances; Data Show Performance to the Right of Fixation

\begin{tabular}{|c|c|c|c|c|c|c|c|c|}
\hline \multirow{3}{*}{$\begin{array}{c}\text { Interletter } \\
\text { Distance } \\
\text { (in degrees) }\end{array}$} & \multicolumn{8}{|c|}{ Letter Location in the String } \\
\hline & \multicolumn{2}{|l|}{4} & \multicolumn{2}{|c|}{5} & \multicolumn{2}{|l|}{7} & \multicolumn{2}{|l|}{9} \\
\hline & $\%$ Correct & $S D$ & $\%$ Correct & $S D$ & \% Correct & $S D$ & $\%$ Correct & $S D$ \\
\hline .06 & 75.0 & 17.3 & 63.3 & 18.2 & 47.5 & 17.1 & 28.3 & 13.4 \\
\hline .12 & 70.8 & 13.1 & 61.7 & 14.0 & 39.2 & 14.4 & 27.5 & 13.6 \\
\hline .18 & 69.2 & 14.4 & 59.2 & 19.3 & 36.7 & 15.6 & 25.8 & 10.0 \\
\hline .24 & 70.8 & 14.4 & 59.2 & 19.8 & 28.3 & 11.9 & 21.6 & 14.7 \\
\hline .30 & 62.5 & 15.4 & 50.8 & 14.4 & 29.2 & 12.4 & 20.0 & 14.6 \\
\hline
\end{tabular}




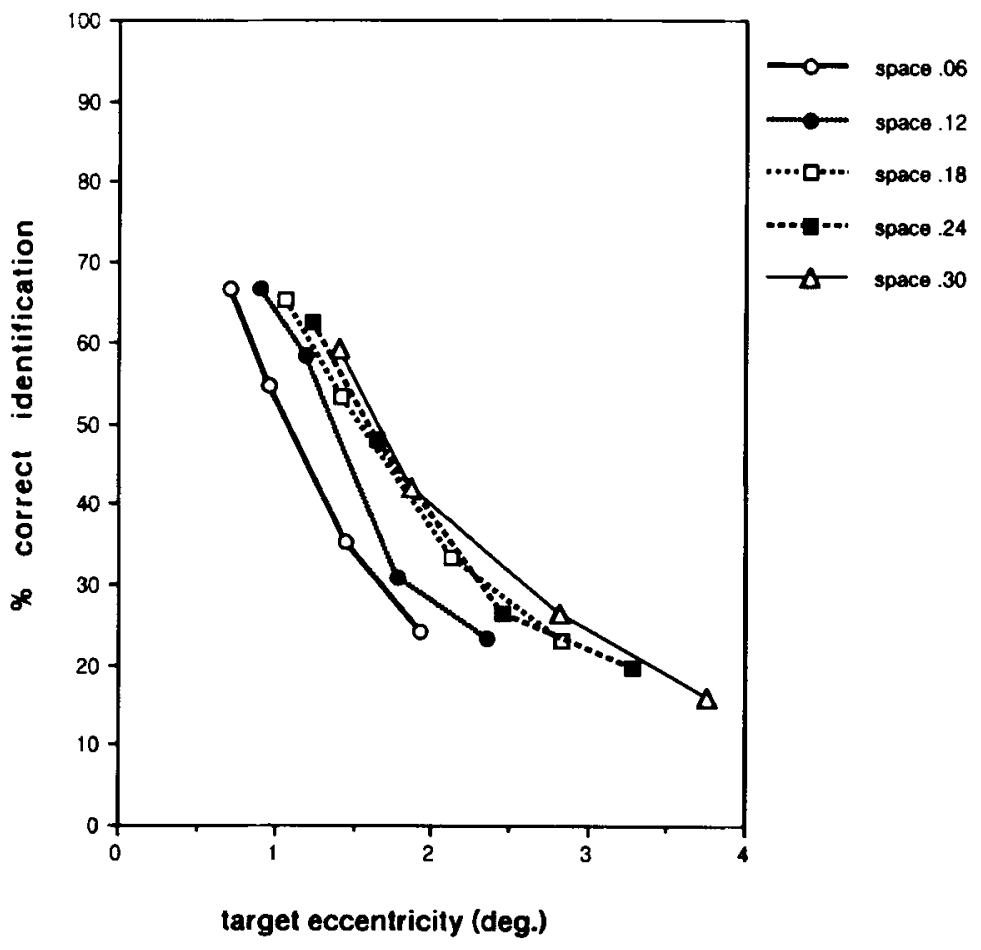

Figure 5. Percent correct letter identification as a function of target eccentricity for the isolated-letter condition and the five different interletter spacings $\left(.06^{\circ}, .12^{\circ}\right.$, $.18^{\circ}, .24^{\circ}$, and $\left..30^{\circ}\right)$.

Materials. One hundred fifty 5-, 7-, and 9-letter common German words (average frequency ranged from 8.6 to 232 per million; Meier, 1964) served as stimuli.

Design and Procedure. Except for the presentation duration, which was set to $85 \mathrm{msec}$, and the length of the word stimuli (5-, 7 -, and 9-letter words), the design and procedure of this experiment were identical to those of Experiment 2.

\section{Results and Discussion}

In Figure 7, the probability of correct word identification for the three different interletter spacings is given as a function of fixation location in the word. Figure 7 shows the data for the 5-, 7-, and 9-letter words. For all three word lengths used, clear effects of interletter spacing and fixation location were obtained. The effect of interletter spacing was significant for 5-letter words $[F(2,28)=$ $7.597, p<.01$ ], 7-letter words $F(2,28)=10.925$, $p<.01]$, and 9-letter words $[F(2,28)=36.96$, $p<.01]$. The effect of fixation location was significant $[F(4,56)=10.043, p<.01 ; F(4,56)=28.195$, $p<.01 ; F(4,56)=45.01, p<.01$, for 5-, 7-, and 9letter words, respectively]. The interaction between fixation location and interletter spacing, which indicates the change in the shape of the curves, was also significant $[F(8,112)=2.217, p<.05 ; F(8,112)=3.728$, $p<.01$; and $F(8,112)=4.924, p<.01$, for 5-, 7-, and 9-letter words, respectively]. For all word lengths, there was a significant quadratic trend $[F(1,14)=35.76$, $p<.01 ; F(1,14)=60.45, p<.01$; and $F(1,14)=$
$108.05, p<.01$, for 5-, 7-, and 9-letter words, respectively], and the interactions between this trend and interletter spacing were significant as well $[F(2,28)=3.34$, $p<.05 ; F(2,28)=5.23, p<.025$; and $F(2,28)=$ $13.49, p<.01$, for 5-, 7- and 9-letter words, respectively].

Table 5 shows the estimation of Parameters $A, B$, and $C$ as a result of fitting the model specified by Equation 1 to the curves of Figure 7. Except for the smallest interletter space for the 5-letter words, for all other conditions, Parameters $A$ and $B$ decreased with increasing interletter space. Thus, as expected from the letter-in-string data, even for short words, the OVP phenomenon becomes stronger when letter visibility decreases.

The assumption of the simple model concerning the relation between letter visibility and the viewing-position effect thus seems to be supported. Modifying the dropoff rate of letter visibility changes, in the predicted way, the shape of the curve that indicates word-recognition performance as a function of fixation location (we will refer to this curve as the word-recognition curve). Unfortunately, any kind of manipulation of letter visibility also affects the global shape of a word. Since it is known that destroying word shape (e.g., aTtEmPt) decreases the recognizability of words (e.g., McClelland, 1976; Rudnicky \& Kolers, 1984), the obtained drop of performance for spaced words might not be purely due to decreasing letter visibility. Furthermore, Campbell and Mewhort 


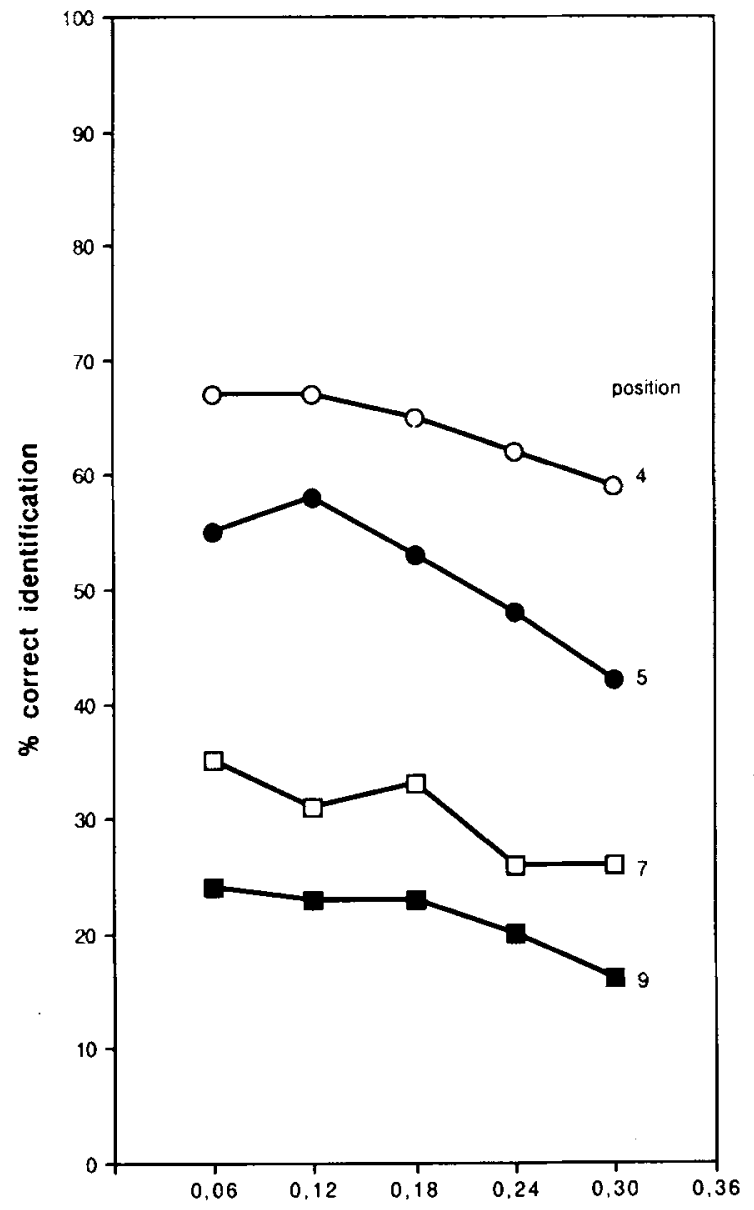

inter letter space (deg.)

Figure 6. Percent correct letter identification as a function of interletter space $\left(.06^{\circ}, .12^{\circ}, .18^{\circ}, .24^{\circ}\right.$, and $\left..30^{\circ}\right)$ for the five target positions in the string (4th, 5th, 7th, and 9 th Jetter positions).
(1980) and Mewhort, Marchetti, and Campbell (1982) provided evidence that letter spacing affects a process in addition to its role in controlling basic visibility, namely, the letter-to-word integration process. However, in the word-recognition curves, manifestations of the effects caused by manipulations of the global word shape should be different from those caused by manipulations of the visibility of individual letters. Since global shape information concerns, by definition, the word as a whole, its contribution to recognition should be independent of the location of the eye in the word. Similarly, a disturbed letter-to-word integration process, which must be located after letter information extraction, should be equally disturbed when the center, the beginning, or the ending of the word is fixated: the effect should be manifested in the intercept (Parameter $A$ ) but not, as obtained in the present experiments, in the shape (Parameter $B$ ) of the curves. Thus, if we can show that by destroying only the global word shape (without affecting letter visibility) the viewingposition effect remains the same as for words with intact word shapes, our conclusion concerning the relation between the OVP phenomenon and letter visibility is supported.

A final experiment was run in which performance on words with intact shapes and high letter visibility (normally spaced lowercase words, e.g., attempt) was compared with performance on words with destroyed shapes but comparable letter visibility (normally spaced mixedcase words: aTtEmPt) and with performance on words with (almost) intact shapes but inferior letter visibility (widely spaced lowercase words: $a_{-} t_{-} t_{-} e_{-} m_{-} p_{-} t$ ). Since, by hypothesis, global shape manipulations affect the intercept but not the shape of the word-identification curve, we expected the viewing-position effect to be as strong for mixed-case words as for normally spaced lowercase words. Overall performance should, however, be higher in the latter case. We expected, as was the case in Experiments 2 and 4, that the viewing-position effect
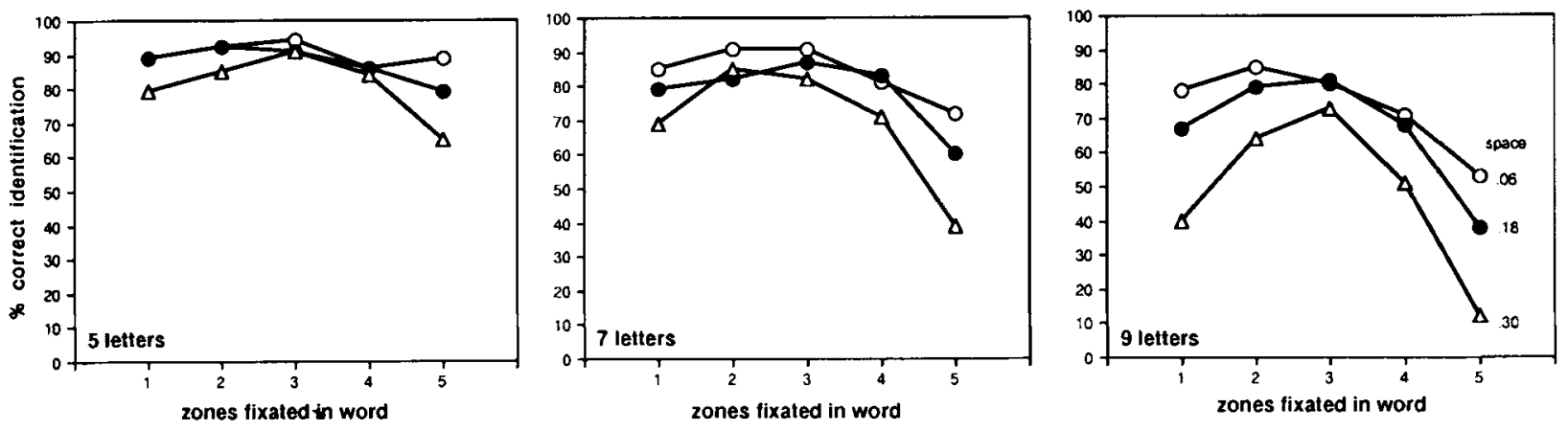

Figure 7. Percent correct word identification as a function of fixated zones in the word for the three different interletter spacings $\left(.06^{\circ}\right.$, $.18^{\circ}$, and $.30^{\circ}$ ). Note that Zone 3 indicates performance while the eye is fixating the 3rd letter in 5-letter words, the 4th letter in 7-letter words, and the 5 th letter in 9-letter words. 
Table 5

Estimated Values of the Parameters $A, B$, and $C$ (With an Interval of Confidence of 95\%) and the Multiple $r^{2}$ as a Function of Interletter Distances for the 5-, 7-, and 9-Letter

Words as a Result of Fitting the Model Specified by Equation 1 to the Curves of Figure 7

\begin{tabular}{|c|c|c|c|c|}
\hline \multirow{2}{*}{$\begin{array}{l}\text { Interletter } \\
\text { Distance } \\
\text { (in degrees) }\end{array}$} & \multicolumn{4}{|c|}{ Parameter } \\
\hline & $A$ & $B$ & $C$ & $r^{2}$ \\
\hline \multicolumn{5}{|c|}{5 Letters } \\
\hline $\begin{array}{l}.06 \\
.18 \\
.30\end{array}$ & $\begin{array}{l}91.6(87.5-95.7) \\
92.1(87.8-96.4) \\
90.2(84.1-96.3)\end{array}$ & $\begin{array}{l}-0.71(-2.37--0.94) \\
-1.71(-3.51--0.08) \\
-4.38(-6.76--2.00)\end{array}$ & $\begin{array}{l}2.49(0.67-4.30) \\
2.26(1.27-3.26) \\
2.67(2.30-3.03)\end{array}$ & $\begin{array}{l}.983 \\
.979 \\
.958\end{array}$ \\
\hline \multicolumn{5}{|c|}{7 Letters } \\
\hline $\begin{array}{l}.06 \\
.18 \\
.30\end{array}$ & $\begin{array}{l}90.8(85.9-95.7) \\
87.5(81.0-94.0) \\
86.1(79.0-93.1)\end{array}$ & $\begin{array}{l}-2.76(-4.78--0.74) \\
-4.43(-6.99--1.87) \\
-7.38(-10.21--4.55)\end{array}$ & $\begin{array}{l}2.32(1.67-2.98) \\
2.57(2.15-2.99) \\
2.50(2.20-2.80)\end{array}$ & $\begin{array}{l}.972 \\
.949 \\
.926\end{array}$ \\
\hline \multicolumn{5}{|c|}{9 Letters } \\
\hline $\begin{array}{l}.06 \\
.18 \\
.30\end{array}$ & $\begin{array}{l}83.8(77.2-90.3) \\
82.5(74.4-90.7) \\
71.6(63.8-79.3)\end{array}$ & $\begin{array}{r}-3.81(-6.60--1.06) \\
-7.10(-10.36--3.83) \\
-11.24(-14.27--8.20)\end{array}$ & $\begin{array}{l}2.16(1.41-2.92) \\
2.50(2.14-2.86) \\
2.69(2.51-2.87)\end{array}$ & $\begin{array}{l}.933 \\
.896 \\
.855\end{array}$ \\
\hline
\end{tabular}

would be greater for the widely spaced lowercase words than for the normally, spaced words.

\section{EXPERIMENT 5}

\section{Method}

Subjects. Fifteen unpaid German students from the University of Aachen participated in this experiment for course credit. All had normal or corrected-to-normal vision.

Materials. One hundred fifty 7-letter and 9-letter common German words (average frequency range was within 11.9-383.5 per million; Meier, 1964) served as stimuli. The words were divided into three lists, each containing 50 words of each length.

Design and Procedure. The experiment contained three blocks. In each block, the words of one of the three lists were presented in one of three conditions: normally spaced lowercase words (interletter space $=.06^{\circ}$ ), normally spaced mixed-case words (interletter space $=.06^{\circ}$ ), and widely spaced lowercase words (interletter space $\left.=.30^{\circ}\right)$. A Latin-square design was used to determine which of the three lists were attributed to which condition. Otherwise, the design and procedure of Experiment 5 were identical to those of Experiment 4.

\section{Results and Discussion}

In Figure 8, the probability of correct word identification for the three different word-type conditions (normally spaced lower-case words, normally spaced mixed-case words, and widely spaced lowercase words) is given as a function of fixation location in the word. The figure shows the data for the 7- and 9-letter words, respectively. For the two word lengths, clear effects of word type and fixation location were obtained. A comparison of performance for normally and widely spaced lowercase 7 - and 9-letter words showed a significant effect of fixation location $[F(4,56)=18.356, p<.01$, and $F(4,56)=$ $31.92, p<.01$, respectively $]$ and word type $[F(1,14)=$
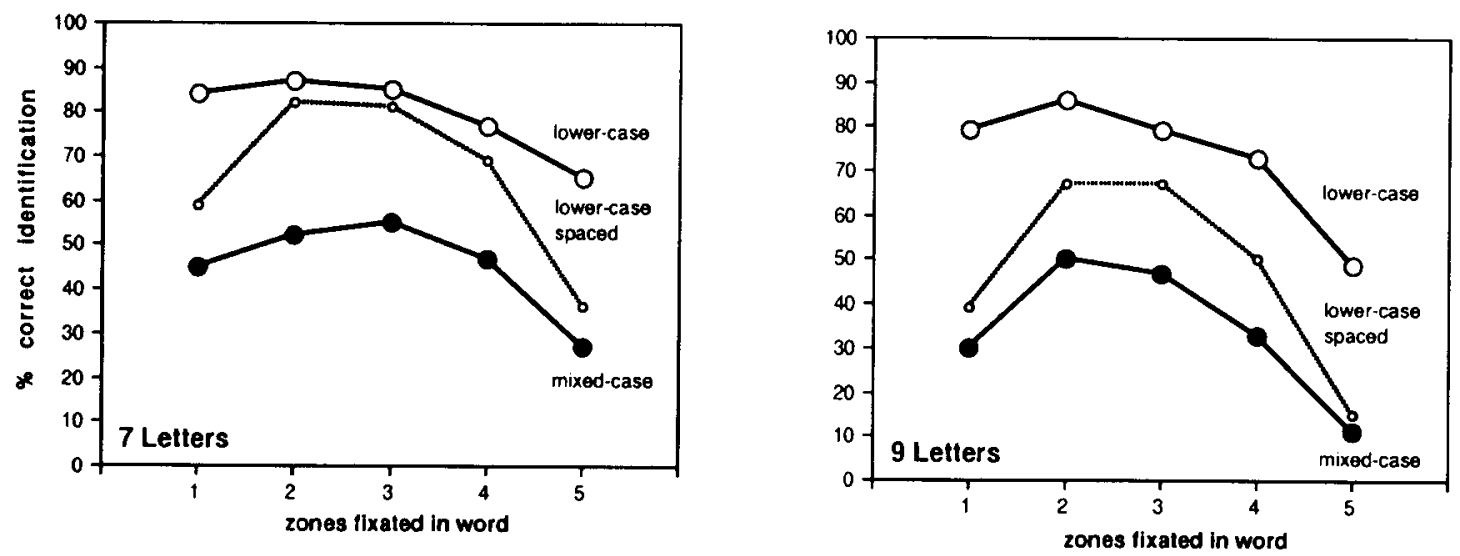

Figure 8. Percent correct word identification as a function of fixated zones in the word for the three different word types (attempt; $\left.a_{-} t_{-} t_{-} e_{-} m_{-} P_{-} t ; a T t E m P t\right)$. Note that Zone 3 indicates performance while the eye is fixating the 4th letter in 7 -letter words and the 5th letter in 9-letter words. 
Table 6

Estimated Values of the Parameters $A, B$, and $C$ (With an Interval of Confidence of 95\%) and the Multiple $r^{2}$ as a Function of Word Type for 7- and 9-Letter Words

as a Result of Fitting the Model Specified by Equation 1 to the Curves Shown in Figure 8

\begin{tabular}{|c|c|c|c|c|c|}
\hline \multirow{2}{*}{$\begin{array}{l}\text { Word } \\
\text { Type }\end{array}$} & \multirow{2}{*}{$\begin{array}{c}\text { Interletter } \\
\text { Distance } \\
\text { (in degrees) }\end{array}$} & \multicolumn{4}{|c|}{ Parameter } \\
\hline & & $A$ & $B$ & $C$ & $r^{2}$ \\
\hline \multicolumn{6}{|c|}{7 Letters } \\
\hline $\begin{array}{l}\text { Lowercase } \\
\text { Lowercase } \\
\text { Mixed }\end{array}$ & $\begin{array}{l}.06 \\
.30 \\
.06\end{array}$ & $\begin{array}{l}87.4(82.7-92.2) \\
83.7(76.8-90.6) \\
57.3(50.6-64.1)\end{array}$ & $\begin{array}{l}-2.24(-4.34--0.14) \\
-8.67(-11.38--5.95) \\
-5.48(-8.15--2.80)\end{array}$ & $\begin{array}{l}1.85(0.64-3.07) \\
2.65(2.44-2.87) \\
2.60(2.24-2.94)\end{array}$ & $\begin{array}{l}.967 \\
.924 \\
.858\end{array}$ \\
\hline \multicolumn{6}{|c|}{9 Letters } \\
\hline $\begin{array}{l}\text { Lowercase } \\
\text { Lowercase } \\
\text { Mixed }\end{array}$ & $\begin{array}{l}.06 \\
.30 \\
.06\end{array}$ & $\begin{array}{l}85.3(80.0-90.6) \\
70.3(62.8-77.8) \\
48.6(42.5-54.7)\end{array}$ & $\begin{array}{r}-4.43(-6.71--2.15) \\
-10.48(-13.39--7.56) \\
-6.67(-9.09--4.24)\end{array}$ & $\begin{array}{l}2.17(1.64-2.69) \\
2.70(2.52-2.89) \\
2.59(2.33-2.85)\end{array}$ & $\begin{array}{l}.955 \\
.864 \\
.819\end{array}$ \\
\hline
\end{tabular}

$17.877, p<.01$, and $F(1,14)=60.179, p<.01$, respectively]. The interaction between fixation location and word type was, as expected, also significant $[F(4,56)$ $=5.036, p<.01$, and $F(4,56)=4.023, p<.01$, respectively]. A trend analysis showed a significant quadratic trend for both the 7-and 9-letter words $[F(1,14)=$ $31.37, p<.01$, and $F(1,14)=67.58, p<.01$, respectively]. The interactions between this trend and word type, indicating a change in the curves' shapes, were significant as well $[F(1,14)=14.66, p<.01$, and $F(1,14)=$ $9.87, p<.01$, respectively]. A separate analysis for normally spaced lowercase and mixed-case words showed a significant effect of fixation location $[F(4,56)=11.239$, $p<.01$, and $F(4,56)=31.696, p<.01$, respectively] and word type $[F(1,14)=115.206, p<.01$, and $F(1,14)=181.044, p<.01$, respectively]. The interaction between the two factors was, however, not significant $[F(4,56)=0.572$ and $F(4,56)=1.566$, respectively]. Similarly, the trend analysis showed a significant quadratic trend $[F(1,14)=35.71, p<.01$, and $F(1,14)=68.68, p<.01$, respectively], but the interaction between the quadratic trend and word type, indicating different curve shapes, was again not significant $[F(1,14)=1.13$ and $F(1,14)=3.32$, respectively $]$.

Table 6 shows the estimation of Parameters $A, B$, and $C$ as a result of fitting the model specified by Equation 1 to the curves in Figure 8. As was the case in Experiments 2 and 4, for the widely spaced word condition, Parameter $A$ decreased slightly and Parameter $B$ decreased strongly as compared with the normal lowercase words. Although different subjects participated in Experiment 5, the results are highly similar to those obtained under the same conditions in Experiment 4 (see Table 4). The viewing-position effect seems thus to be a robust phenomenon. For the mixed-case condition, $\mathrm{Pa}$ rameter $A$ decreased greatly, as expected. Parameter $B$ decreased as well, although not as much as it did for the widely spaced words. However, since the interaction between the quadratic trend and word type was not significant, we will consider that the empirical curves do not reliably differ in their shapes. In summary, we can say that destroying global word information has its effect on the intercept and not on the shape of the wordrecognition curve. Although overall performance was lower for the mixed-case words than for the normally spaced lowercase words, the viewing position effect remained the same. For the widely spaced lowercase wotds, however, as predicted by the letter visibility model, a clear change of the shape of the word-recognition curves was obtained. Given these results, it seems difficult to argue that the strengthening of the OVP effect obtained by increasing interletter space (Experiments 2, 4, and 5) was due to distortion of global word information. Of course, it is possible to argue that increasing interletter spacing reduces not only letter visibility, but also the visibility of features of the global word shape. But at that point, the distinction between letters and global word shape starts to become less clear.

\section{GENERAL DISCUSSION}

The results of the present experiments lend support to the assumption that the OVP phenomenon is related to letter visibility (McConkie et al., 1989; Nazir, in press; Nazir et al., 1991; O'Regan, 1989, 1990; O'Regan \& Jacobs, 1992). As predicted by McConkie et al.'s model, word recognition varies more strongly with fixation location when the drop-off rate of available visual information from letters increases: the OVP phenomenon is amplified when, due to increasing interletter spacing, letter visibility is reduced. (That increasing interletter space actually reduces letter visibility is shown by the results of the letter-in-string experiments.) The fact that the OVP is not exactly in the center of the word does not violate this assumption, since this asymmetry can also be explained by letter visibility, which is better to the right than to the left of fixation (see Experiments 1 and 3). Using a letter-discrimination task, Nazir et al. (1991) estimated the left/right asymmetry of letter visibility to be $1.8 / 1$; while the probability of correct letter discrimination 
dropped by $1 \%$ when the letter was presented to the right of fixation, it dropped by $1.8 \%$ when it was presented to the left. ${ }^{1}$ This asymmetry factor is in fact very close to the one obtained for visual span during reading when only letter identity is considered. Changing the identity of a letter in a word during ongoing reading affects eyemovement behavior only if the critical letter is closer than 8 letters to the right and 4 letters to the left of fixation, leading to an asymmetry factor of 2:1 (Rayner, Well, \& Pollatsek, 1980; Underwood \& McConkie, 1985). Using the asymmetric probability of letter discrimination, and making the simplifying assumption that, to recognize a word, all letters of the word must be identified independently, Nazir et al. (1991) and Nazir (in press) calculated the probability of recognizing a word from different fixation locations by multiplying the recognition probabilities of individual letters. A comparison of the calculated word-recognition probability to empirical results showed a fairly good fit. However, as suggested by the results of the present Experiments 1 and 3, the asymmetry seems to change with presentation duration: it becomes stronger when presentation duration decreases. It is interesting that this change is evident in the word experiment as well. With a shorter presentation duration, the OVP is more leftward. If we compare the 9-letter words in Experiments 2 and 4, Parameter $C$, which indicates the OVP, varied between 2.5 and 2.8 (see Table 3 ) in the first case, and between 2.2 and 2.7 (see Table 5) in the second. The reason why $C$ increases with increasing interletter spacing is not clear at the moment. Further experimentation is needed before something can be said about the mechanisms underlying this asymmetry.

Both the obtained sensitivity of fixation-dependent word-recognition performance to variations of letter visibility and the compatibility between the noncentral location of the OVP and asymmetrical letter-recognition performance to both sides of fixation indicate that the OVP phenomenon is suggestive as to the role of letters in word recognition. Given the results of Experiment 5, where it could be shown that effects of global word-shape distortion are manifested differently in the word-recognition curves than are effects of letter visibility, the variable viewing-positions paradigm might be an interesting method to distinguish the contributions of letter and supraletter information (like the global word shape) to word recognition. To put these results into the framework of the old controversy of analytic letter-based models and holistic word-shape-based models of word recognition (e.g., Cattell, 1885; Erdmann \& Dodge, 1898; Korte, 1923; Zeitler, 1900), which has had a revival in recent works (e.g., Allen \& Madden, 1990; Healy, Oliver, \& McNamara, 1987), would, however, be the wrong approach. What is called for seems not to be a decision as to whether letter information or global word-shape information triggers word recognition, but how strong the contribution of each of these factors is under a given condition. An elaborated version of the letter-in-string experiment, where (as is the case in words) the target letters have to be identified in nonhomogeneous strings of letters, combined with the variable viewing-positions paradigm, might provide a tool to estimate the relative weight of visual and lexical constraints active in word recognition (see Nazir et al., 1991).

\section{REFERENCES}

Allen, P. A., MAdDEN, D. J. (1990). Evidence for a parallel input serial analysis model of word processing. Joumal of Experimental Psychology: Human Perception \& Performance, 16, 48-64.

Boums, H. (1970). Interaction effects in parafoveal letter recognition. Nature, 226, 177-178.

Bouma, H. (1973). Visual interference in the parafoveal recognition of initial and final letters of words. Vision Research, 13, 767-782.

BoumA, H. (1978). Visual search in reading: Eye movements and functional visual field: A tutorial review. In J. Requin (Ed.), Attention \& performance VII (pp. 115-145). Hillsdale, NJ: Erlbaum.

Bouma, H., \&egein, C. P. (1977). Foveal and parafoveal recognition of letters and words by dyslexics and by average readers. Neuropsychologia, 15, 69-80.

Brysbaert, M., D'Ydewalle, G. (1988). Collosal transmission in reading. In G. Lüer, U. Lass, \& F. Shallo-Hoffmann (Eds.), Eye movement research: Physiological and psychological aspects (pp. 246266). Göttingen: Hogrefe.

CAmpbell, A. J., M MEWhORT, D. J. K. (1980). On familiarity effects in visual information processing. Canadian Journal of Psychology, 34, 134-154.

CATtell, J. M. (1885). Über die Zeit der Erkennung und Benennung von Schriftzeichen, Bildern und Farben. Philosophische Studien, 2, 635-650.

Erdmann, B., \& Dodge, R. (1898). Psychologische Untersuchungen uber das Lesen auf experimenteller Grundlage. Halle: Niemeyer.

Hagenzieker, M. P., van der Heuden, A. H. C., Hagenaar, R. (1990). The time courses in visual-information processing: Some empirical evidence for inhibition. Psychological Research/Psychologische Forschung, 52, 13-21.

Healy, A. F., Oliver, W. L., McNamara, T. P. (1987). Detecting letters in continuous text: Effects of display size. Joumal of Experimental Psychology: Human Perception \& Performance, 13, 279-290.

JACOBS, R. J. (1979). Visual resolution and contour interaction in the fovea and periphery. Vision Research, 9, 1187-1196.

KORTE, W. (1923). Uber die Gestaltauffassung im indirektem Sehen. Zeitschrift fiur Psychologie, 93, 17-82.

McClelland, J. (1976). Preliminary letter identification in the perception of words and non-words. Joumal of Experimental Psychology: Human Perception \& Performance, 2, 80-91.

McConkie, G. W., Kerr, P. W., Reddix, M. D., Zola, D., JACOBS, A. M. (1989). Eye movement control during reading: II. Frequency of refixating a word. Perception \& Psychophysics, 46, 245-253. MCCONKIE, G. W., RAYNER, K. (1976). Asymmetry of the perceptual span in reading. Bulletin of the Psychonomic Society, 8, 365-368.

MeIER, H. (1964). Deutsche Sprachstatistik (Vol. 2). Hildesheim: Georg Olms.

Mewhort, D. J. K., Marchetti, F. M., Campbell, A. J. (1982). Blank characters in tachistoscopic recognition: Space has both a symbolic and a sensory role. Canadian Joumal of Psychology, 36, 559-575.

NAziR, T. A. (1991). On the role of refixations in letter strings: The influence of oculomotor factors. Perception \& Psychophysics, 49, 373-389.

NAZIR, T. A. (in press). On the relation between the optimal and the preferred viewing position in words during reading. In J. v. Rensbergen \& G. D'Ydewalle (Eds.), Studies in visual information processing. Amsterdam: North-Holland.

NAZ1R, T. A., O'Regan, J. K., JaCobs, A. M. (1991). On words and their letters. Bulletin of the Psychonomic Society, 29, 171-174. 
Olzak, L. A., Thomas, J. P. (1986). Seeing spatial pattern. In K. R. Boff, L. Kaufman, \& J. P. Thomas (Eds.), Handbook of perception and human performance (Vol. 2, pp. 7:1-7:56). New York: Wiley.

O'ReGAN, J. K. (1989). Visual acuity, lexical structure, and eye movements in word recognition. In B. Elsendoorn \& H. Bouma (Eds.), Working models of human perception (pp. 261-292). London: Academic Press.

O'RegAN, J. K. (1990). Eye movements and reading. In E. Kowler (Ed.), Eye movements and their role in visual and cognitive processes (Reviews of Oculomotor Research, Vol. 4, pp. 395-453). Amsterdam: Elsevier.

O'Regan, J. K., Jacobs, A. M. (1992). The optimal viewing position effect in word recognition: A challenge to current theory. Journal of Experimental Psychology: Human Perception \& Performance, 18, 185-197.

O'REgAN, J. K., \& LÉvy-SCHOEN, A. (1987). Eye movement strategy and tactics in word recognition and reading. In M. Coltheart (Ed.), Attention \& performance XII: The psychology of reading (pp. 363383). Hillsdale, NJ: Erlbaum.

O'Regan, J. K., Lévy-Schoen, A., Pynte, J., \& Brugaillère, B. (1984). Convenient fixation location within isolated words of different length and structure. Joumal of Experimental Psychology: $\mathrm{Hu}$ man Perception \& Performance, 10, 250-257.

Pollatsex, A., Bolozky, S., Well, A. D., \& Rayner, K. (1981). Asymmetries in the perceptual span for Israeli readers. Brain \& Language, 14, 174-180.

Rayner, K., Well, A. D., \& Pollatsek, A. (1980). Asymmetry of the effective visual field in reading. Perception \& Psychophysics, 27, 537-544.
Rudnicky, A. I., \& Kolers, P. A. (1984). Size and case of type as stimuli in reading. Journal of Experimental Psychology: Human Perception \& Performance, 10, 231-249.

UNDERWoOd, N. R., \& MCConkIE, G. W. (1985). Perceptual span for letter distinctions during reading. Reading Research Quarterly, 20, 153-162.

VITU, F. (1991). The influence of parafoveal preprocessing and linguistic context on the optimal landing position effect. Perception \& Psychophysics, 50, 58-75.

Vitu, F., O'Regan, J. K., \& Mittau, M. (1990). Optimal landing position in reading isolated words and continuous texts. Perception \& Psychophysics, 47, 583-600.

ZEITLER, J. (1900). Tachistoskopische Untersuchungen über das Lesen. Philosophische Studien, 16, 380-463.

\section{NOTE}

1. Given these different drop-off rates, the left/right asymmetry cannot be due to an inappropriate fixation strategy adopted by the subject (e.g., fixating always slightly toward the right of fixation point), since such a strategy would increase overall performance for letters to the right of fixation (intercept) but it would not affect the drop-off rate (slope)

(Manuscript received July 8, 1991; revision accepted for publication February 29, 1992.) 